\title{
Evolution of discocephalid ciliates: Molecular, morphological and ontogenetic data support a sister group of discocephalids and pseudoamphisiellids (Protozoa, Ciliophora) with establishment of a new suborder Pseudoamphisiellina subord. $n$.
}

\author{
MIAO Miao ${ }^{1}$, SHAO Chen $^{1,2}$, CHEN XuMiao $^{1} \&$ SONG WeiBo $^{1 *}$ \\ ${ }^{1}$ Laboratory of Protozoology, Institute of Evolution and Marine Biodiversity, Ocean University of China, Qingdao 266003, China; \\ ${ }^{2}$ School of Life Science and Technology, Xi'an Jiaotong University, Xi'an 710049, China
}

Received February 7, 2011; accepted June 17, 2011

\begin{abstract}
Discocephalids and pseudoamphisiellids are possibly two of the most confused groups among hypotrichous/euplotid ciliates regarding their systematic position and phylogenetic relationships. The former were often regarded as related to euplotids while the latter, in the absence of molecular data, were mostly assigned to the urostylid-like hypotrichs. In the present work, the small subunit rRNA genes of several rarely observed discocephalid and pseudoamphisiellid genera were analyzed to obtain insights into the phylogenetic relationships of these highly ambiguous Spirotrichea. Four different tree reconstruction algorithms yielded nearly identical topologies, which indicated both groups belong to the same assemblage. This assemblage is clearly isolated as a deep-branching clade and invariably positioned between Euplotida and Hypotricha. The sister group relationship of the Pseudoamphisiellidae and Discocephalidae supports the previous suggestion that they might represent an ordinal taxon, the Discocephalida. Both morphological and morphogenetic features indicate that the pseudoamphisiellids should be placed in the order Discocephalida but as a sister group to other typical discocephalids. Thus we propose establishing a new suborder, Pseudoamphisiellina subord. $\mathrm{n}$. The new taxon is diagnosed by the following characteristics: (i) two distantly separated midventral rows that are morphogenetically formed with an urostylid mode; (ii) absence of the "frontoterminal row", which is formed from the posterior-most frontoventral-transverse cirral anlage in all other typical urostylids; (iii) numerous caudal cirri that derive from each of the dorsal kinety anlagen; (iv) right marginal row that has a unique de novo origin; and (v) inhabiting periphytic communities. The validity of the suborder Pseudoamphisiellina is firmly supported by molecular data.
\end{abstract}

Ciliophora, Discocephalida, Pseudoamphisiellina subord. n., new suborder, phylogeny, SSU rRNA gene

Citation: Miao M, Shao C, Chen X M, et al. Evolution of discocephalid ciliates: Molecular, morphological and ontogenetic data support a sister group of discocephalids and pseudoamphisiellids (Protozoa, Ciliophora) with establishment of a new suborder Pseudoamphisiellina subord. n.. Sci China Life Sci, 2011, 54: 634-641, doi: 10.1007/s11427-011-4192-8

The class Spirotrichea is one of the most diverse groups of ciliated protozoa inhabiting marine biotopes. The morphological and morphogenetic diversity of spirotrichs, together with their ecological importance, make them the most studies of all ciliates. Two groups of hypotrich ciliates, discocephalids and pseudoamphisiellids, characterized by a

*Corresponding author (email: wsong@ouc.edu.cn) unique combination of many morphological and morphogenetic features, are extremely problematic in their placement in the class Spirotrichea (sensu Lynn 2008) or in hypotrichs (sensu Berger 2006). The discocephalids have been repeatedly recognized as a euplotid group [1-5], whereas pesudoamphisiellids are always considered a highly specialized hypotrichous taxon [2,3,6-8]. The systematic positions of these two groups have not yet been rigorously verified as 
only two genera, Prodiscocephalus and Pseudoamphisiella, have been investigated genetically based on small subunit (SSU) rRNA gene sequences [7-9].

In the present study, we focused on these two groups and used all molecular information available, including two genera of discocephalids (Paradiscocephalus and Discocephalus) and one genus of the family Pseudoamphisiellidae (Leptoamphisiella). Our primary goal was to study the relationships and the phylogenetic placement of these taxa. The findings will provide important insights into the origin and evolution of Spirotrichea, especially the morphologically diverse euplotids and stichotrichs. Moreover, we evaluated the potential utility of SSU rRNA gene sequences for future phylogenetic studies of spirotrichs.

\section{Materials and methods}

\subsection{Samples, DNA extraction, and amplification and sequencing of SSU rRNA genes}

Samples of Leptoamphisiella vermis were collected from the coast of Qingdao $\left(36^{\circ} 04^{\prime} \mathrm{N}, 120^{\circ} 20^{\prime} \mathrm{E}\right)$. Organisms were isolated and identified according to published descriptions [10]. Terminology and classification systems followed Berger [11,12].

Total genomic DNA was extracted using the REDExtract-N-Amp Tissue PCR Kit (Sigma, St Louis, USA). SSU rRNA coding regions were amplified by PCR according to Miao et al. [13], using two primers complementary to the $5^{\prime}$ and 3 ' termini of eukaryotic $16 \mathrm{~S}$-like rRNA genes [14]. The full-length PCR products were purified by agarose gel electrophoresis, cloned in the pUCm-T vector (Sangon, Toronto, ON, Canada), and sequenced on both strands by the Takara sequencing facility, Shanghai, China.

\subsection{Alignment and phylogenetic analysis}

Complete or nearly complete SSU rRNA gene sequences in this study were obtained from the GenBank/EMBL database and aligned manually using BioEdit software [15]. MrModeltest 2 [16] was used to identify the optimal evolutionary model (a general time-reversible model), and showed that among-site rate variation was best modeled with gamma correction $(=0.4631)$ [17] and invariant sites $(=0.2993)$ [18]. A maximum likelihood (ML) analysis was performed using the software PHYML 2.4.4 [19]. For maximum parsimony (MP) analysis in PAUP* 4.0b10 [20], a tree bisection and reconnection (TBR) heuristic search was used with a parsimony ratchet with all characters equally weighted and unordered. Statistical support for the ML and MP analyses was obtained from 1000 bootstrap replicates. The program MrBayes 3.0b4 [21] was used to construct a Bayesian tree using Markov chain Monte Carlo algorithm. The chain length for our analysis was 10000000 generations with trees sampled every 100 generations; the first $25 \%$ were discarded as burn-in. Posterior probabilities (PP) at nodes were estimated from the remaining trees. A cladogram was constructed using the neighbor-joining (NJ) method [22] with the Kimura two-parameter model [23] using the PHYLIP 3.66 package [24]. TreeView 1.6.6 [25] and MEGA 4.0 [26] were used to visualize tree topologies. Finally, a comparison of the likelihood of the best topology with the likelihood of the candidate topologies (shown below) was performed with the approximately unbiased (AU) test [27] implemented in PAUP* $4.0 b 10$ [20]. The test determines whether the alignment shows significant conflict with the favored topology.

\section{Results}

\subsection{Sequence comparison}

The target SSU rRNA nucleotide sequence of Leptoamphisiella vermis is $1776 \mathrm{bp}$ in length (GenBank accession No. FJ865203). We compared the complete SSU rRNA gene sequence among discocephalids and pseudoamphisiellids. Paradiscocephalus elongatus and Prodiscocephalus borrori showed 36 bp differences in the primary structure of the SSU rRNA gene, a number that is much less than the differences between $P$. elongatus and Discocephalus ehrenbergi (154 bp), and between $D$. ehrenbergi and $P$. borrori (154 bp). Closely related species in the genus Pseudoamphisiella showed sequence differences of 6-103 bp, while $L$. vermis differed from Pseudoamphisiella species by $56-88$ bp.

\subsection{Alignment and SSU rRNA gene genealogy}

Base composition across the entire data set was fairly uniform $(26.5 \% \mathrm{~A}, 19.8 \% \mathrm{C}, 26.1 \% \mathrm{G}$, and $27.6 \% \mathrm{~T})$, and no evidence of saturation was found in the sequences used (data not shown). All major nodes supported by partitioned bootstrap analyses were in agreement.

The pseudoamphisiellid-discocephalid clade was an isolated assemblage, though with alternative affinities (hypotrichs) in all four topologies (MP, ML, BI, and NJ) (data not shown). Sister-grouping of the pseudoamphisiellids and discocephalids was moderately supported by BI posterior probabilities (0.92), but was poorly supported by MP (bootstrap support 56\%) and equivocal in the ML and $\mathrm{NJ}$ analysis (Figures 1 and 2). Consistently, Discocephalus was sister to Prodiscocephalus and Paradiscocephalus, (Figures 1 and 2). Pseudoamphisiella lacazei was more closely related to $L$. vermis (support values: 53\% ML, 65\% MP, $1.00 \mathrm{BI}, 64 \%$ NJ) than to other Pseudoamphisiella species.

Using the AU test, we tested the likelihood of the following five topologies against the best ML topology: (i) hypotrichs (including the family Urostylidae) are mono- 


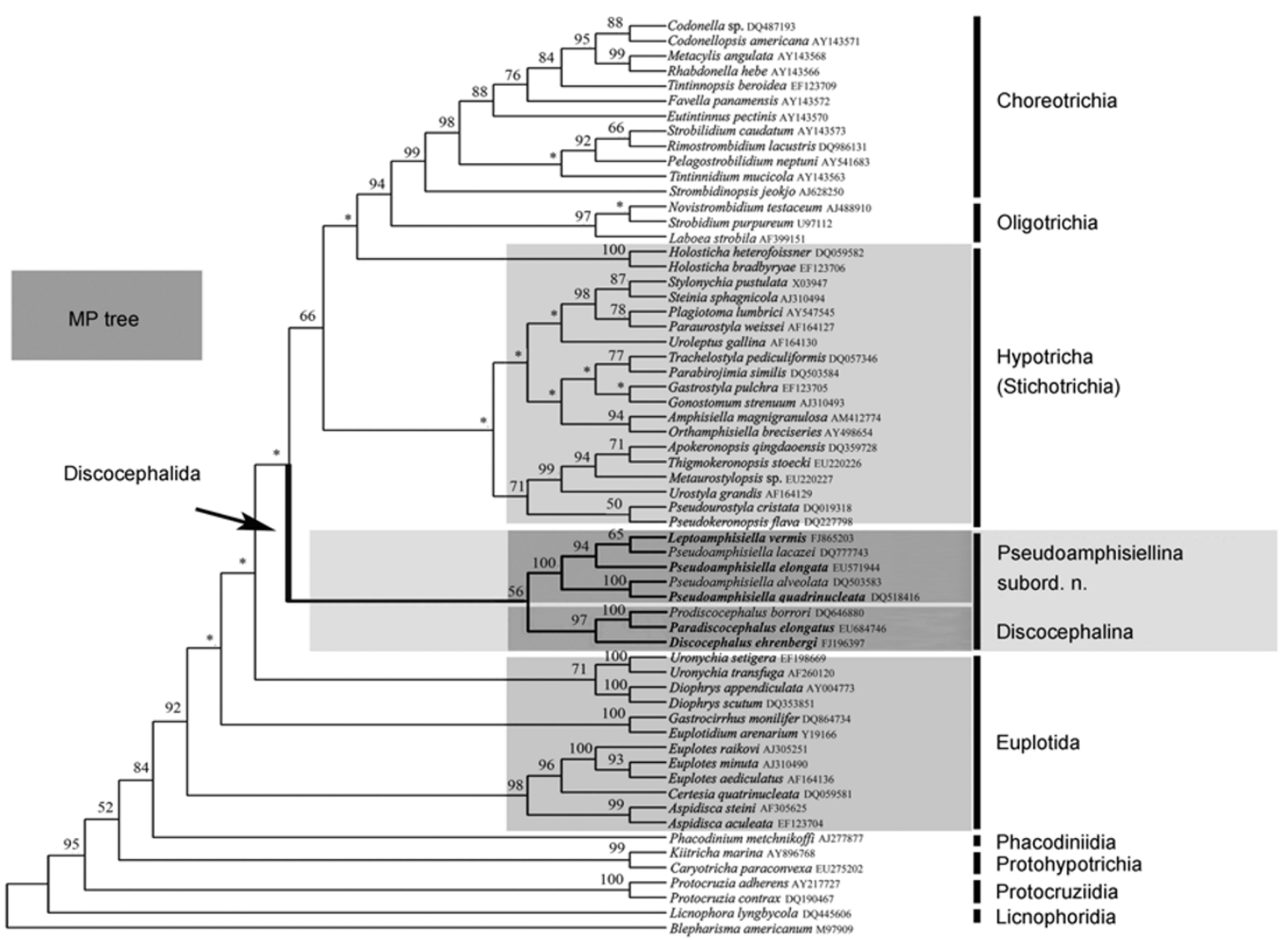

Figure 1 Maximum parsimony (MP) phylogeny of spirotrichous ciliates constructed from complete SSU rRNA gene nucleotide sequences. The numbers at the forks indicate the percentage of times that specific branch pattern occurred in 1000 trees. No significance is placed on branch lengths connecting the species. The taxa sequenced in our study are highlighted in boldface. Asterisks indicate bootstrap proportions $<50 \%$.

phyletic; (ii) Discocephalida is assigned to the hypotrichs; (iii) Discocephalida is placed within euplotids; (iv) Leptoamphisiella clusters with Pseudoamphisiella; and (v) the genus Pseudoamphisiella is monophyletic. The first $(P=$ $0.078)$, third $(P=0.122)$, and fourth $(P=0.122)$ topologies were accepted, but the other topologies were strongly rejected (i.e., for 2, $P=0.022$; for $5, P=0.004$ ).

\section{Discussion}

\subsection{Discocephalida is clearly separated from euplotids and hypotrichs}

Jankowski [28] placed the discocephalids as a family under the superfamily Oxytrichidea, and thus completely separated from euplotids. Based mainly on morphological features, the Discocephalus-like assemblage has been placed as follows: within the order Euplotida as a suborder along with the suborder of 'true' euplotids [3,29]; assigned to the family Euplotidae [1]; as a suborder within the order 'Hypotrichida' (s. 1.) [5,30]; or as an order within Oxytrichia [31] or in the order Hypotrichida [5].
The morphological and morphogenetic data obtained to date reveal that the discocephalines possess a combination of features that are characteristic of either hypotrichs or euplotids (Table 1). In relation to most hypotrichs, discocephalines share the following features: (i) Both left and right marginal rows are present and formed intrakinetally, which is typical of most hypotrichs; (ii) the oral primordium in the opisthe is generated on the cell surface, hence in epi-apokinetal mode; (iii) the left-most frontal cirrus derives from the anterior end of the undulating membrane (UM)anlage; (iv) many frontoventral-transverse (FVT) cirral anlagen are formed, which is widely regarded to be a plesiomorphic feature shared typically by the "lower" hypotrichs, and hence not the 5-FVT-mode seen commonly in euplotids; and (v) the dorsal kinety anlagen are formed in the secondary mode $[9,11,12,32]$. Discocephalines show also some features characteristic of typical euplotids: (i) the caudal cirri are formed from the rightmost dorsal kineties anlagen with a multi-segmentation mode; and (ii) the development of the FVT-anlagen is of the primary type, although this feature also occurs in some lower hypotrichs [10-12,33-35]. Nevertheless, considering the developmental mode and process, discocephalines are also rather unusual, 


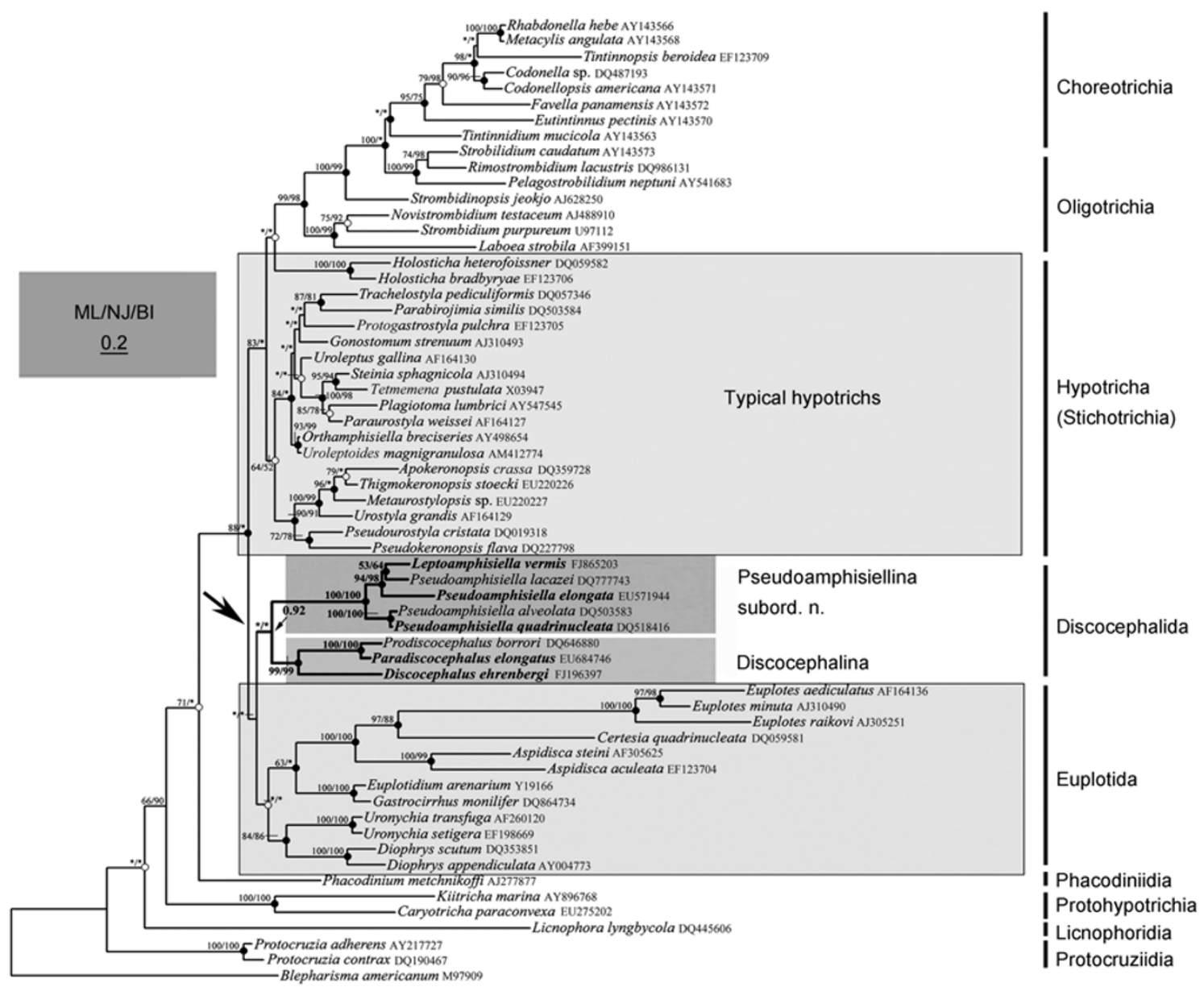

Figure 2 Maximum likelihood (ML) phylogeny of spirotrichous ciliates inferred from complete SSU rRNA gene nucleotide sequences. Numbers at the nodes represent bootstrap values (in \%): $1 \mathrm{P}^{\text {stP }}$ No. $=$ bootstrap values derived from ML method out of 1000 replications, $2 \mathrm{P}^{\text {ndP }}$ No. $=$ bootstrap values derived from the distance matrix-based on the neighbor joining (NJ) method. Dots at nodes represent Bayesian posterior probabilities: a solid dot indicates 1.00 BI, and an open dot indicates $0.95-0.99 \mathrm{BI}$. Asterisks at a given node indicate bootstrap values less than 50\% and/or disagreement between an analytic method and the reference ML tree. Evolutionary distance is represented by the branch length separating the species in the figure. The scale bar corresponds to 20 substitutions per 100 nucleotide positions. The taxa sequenced in our study are highlighted in boldface.

demonstrating features that occur in neither hypotrichs nor in euplotids: (i) migrating cirri are not formed, which are always derived from the right-most cirral anlage in all traditional hypotrichs; and (ii) the UM-anlage splits transversely to form the endoral and paroral membranes, whereas the UM-anlage typically splits longitudinally $[5,9]$.

Our SSU rRNA gene-based analyses yielded two possible relationships, although both with low bootstrap values $(<50 \%)$ : The topology of the ML/NJ trees indicated a close relationship between the pseudoamphisiellid-discocephalid clade and the subclass Euplotida (Figure 2); the MP topology indicated the clade to be an intermediate group, divergent from the assemblage of hypotrichs-choreotrichsoligotrichs (Figure 1).

Therefore, a hypothesis to explain the confusing suite of morphological and morphogenetic characters that seems to be characteristic of euplotids/hypotrichs can be formulated by focusing on the apparently basal (or divergent) relationship to pseudoamphisiellid-discocephalid. Different structural and developmental features of organisms do not nece- ssarily evolve at the same rate. Therefore, the morphological/morphogenetic similarities may be plesiomorphies, and the conflicting mixture of characteristics seen in discocephalids may derive from different rates of character evolution. This supports ranking it at least as an ordinal taxon, as suggested by Shao et al. [9].

In conclusion, all of the above morphological and morphogenetic characteristics and molecular data indicate that discocephalids might represent a taxon intermediate between euplotids and hypotrichs. Nevertheless, as the AU test rejects their placement with subclass Hypotricha and there are significant morphological and morphogenetic differences compared to other hypotrichs, we propose elevating the suborder Discocephalina to ordinal status within the subclass Hypotricha.

\subsection{Relationships of Discocephalus, Paradiscocephalus, and Prodiscocephalus}

Discocephalids have a distinct discoid "head" followed by 
Table 1 Comparison of ontogenetic characteristics among three higher hypotrichous groups. Alv, Pseudoamphisiella alveolata; Asp, Aspidisca; AZM, adoral zone of membranelles; Diop, Diophrys; Dis, Discocephalus; DK, dorsal kineties; Elon, Pseudoamphisiella elongata; Eup, Euplotes; FVT-anlagen, frontoventral-transverse cirral anlagen; Lac, Pseudoamphisiella lacazei; Mar, Marginotricha; Prod, Prodiscocephalus; UM, undulating membranes; Uron, Uronychia $^{\text {a) }}$

\begin{tabular}{|c|c|c|c|c|}
\hline Characteristics & Hypotrichs & Euplotids $^{\S}$ & Pseudoamphisiellines & Discocephalines \\
\hline \multirow[t]{2}{*}{ Fate of old AZM } & completely retained $^{\&}$ & $\begin{array}{c}\text { completely retained (Eup \& } \\
\text { Asp) }\end{array}$ & $\begin{array}{c}\text { completely renewed (Lac \& } \\
\text { Elon) }\end{array}$ & completely retained (Dis) \\
\hline & partly or completely renewed $^{\dagger}$ & partly renewed (Diop \& Uron) & partly renewed (Alv) & partly renewed (Mar \& Prod) \\
\hline $\begin{array}{l}\text { Fate of old undulating mem- } \\
\text { branes }\end{array}$ & completely renewed & $\begin{array}{c}\text { retained (Eup \& Asp) } \\
\text { completely renewed (Diop \& } \\
\text { Uron) }\end{array}$ & completely renewed & completely renewed \\
\hline $\begin{array}{c}\text { Origin of the opisthe's oral } \\
\text { primordium }\end{array}$ & on cell surface & $\begin{array}{l}\text { within a subsurface pouch, } \\
\text { beneath the pellicle }\end{array}$ & on cell surface & on cell surface \\
\hline $\begin{array}{c}\text { Origin of the left-most frontal } \\
\text { cirrus }\end{array}$ & typically from UM-anlage & $\begin{array}{l}\text { formed de novo near the old } \\
\text { UM }\end{array}$ & from UM-anlage & from UM-anlage \\
\hline FVT-cirral anlagen, number & $\begin{array}{l}\text { both 5- anlagen }{ }^{\&} \text { and more } \\
\text { than } 5^{\dagger}\end{array}$ & invariably 5-anlagen & more than 5 & more than 5 \\
\hline Type of development of & almost absolutely & primary mode & primary mode (Alv \& Elon) & primary mode \\
\hline FVT-anlagen & secondary mode ${ }^{\&}$ & & secondary mode (Lac) & \\
\hline Marginal anlagen & $\begin{array}{l}\text { mostly intrakinetally } \\
\text { less de novo }\end{array}$ & de novo & intrakinetally & intrakinetally \\
\hline Dorsal kinety anlagen & mostly two-group type ${ }^{\#_{\&}}$ & one-group type & one-group type & one-group type \\
\hline DK formation mode ${ }^{*}$ & $\begin{array}{l}\text { less commonly one group } \\
\text { secondary }\end{array}$ & primary & secondary & secondary \\
\hline Origin of dorsal kineties & $\begin{array}{l}\text { within left parental rows, } \\
\text { followed by fragmentation in } \\
\text { right-most row }{ }^{\&} \\
\text { intrakinetally or de novo }\end{array}$ & $\begin{array}{c}\text { within each of parental one, } \\
\text { no fragmentation }\end{array}$ & $\begin{array}{c}\text { within each of parental one, } \\
\text { no fragmentation }\end{array}$ & $\begin{array}{l}\text { within each of parental one, } \\
\text { no fragmentation }\end{array}$ \\
\hline Formation of caudal cirri & $* *$ & $\begin{array}{c}\text { right-most one(s) generating } \\
\text { one or } \\
\text { more caudal cirri (euplotid } \\
\text { mode) }\end{array}$ & $* *$ & $* * *$ \\
\hline Data sources & {$[12,13]$} & {$[33,34,36,37]$} & {$[32,38]$} & {$[5,9]$} \\
\hline
\end{tabular}

a) \&, basically genera in the oxytrichid complex (s. 1.). $\dagger$, typical in urostylids. $\S$, including genera for which morphogenesis is well characterized (e.g., Euplotes, Diophrys, Uronychia and Aspidisca). \#, one group generates intrakinetally from the parental dorsal kineties, the other is formed de novo dorsal-marginally. *, initially as one group (primary mode) and then divides into two sets, one for each divider; or initially as two groups for two daughter cells (secondary mode). **, when present, each dorsal kinety anlage generates only one caudal cirrus. ***, multi-segmentation mode.

the body region [3]. Considering the general morphology, three genera have been discussed recently. Paradiscocephalus was not only mainly characterized by common Discocephalus-like features (e.g., the discoid 'head', posterolateral marginal row, general ciliary pattern, and well-developed transverse cirri), but also by special pairs of cortical granules and by ventral cirri arranged in a sparse zig-zag pattern corresponding to pseudoamphisiellids. The genera Discocephalus and Prodiscocephalus are similar to Paradiscocephalus, but have a tiny difference in the arrangement of ventral cirri (several unaligned and widely separated ventral cirri vs. ventral cirri arranged in an indistinct zig-zag pattern) [6,39]. The systematic relationship of these three genera has never been examined previously using molecular data. Our analyses of SSU rRNA gene sequences show consistently that Prodiscocephalus, Paradiscocephalus and Discocephalus share a common ancestry (99\% ML, $1.00 \mathrm{BI}, 99 \% \mathrm{NJ}, 97 \% \mathrm{MP})$. Our results also demonstrated that Prodiscocephalus is closer to Paradiscocephalus, which is not congruent with their morphology.

\subsection{The family Pseudoamphisiellidae belongs to the order Discocephalida}

The systematic position of the genus Pseudoamphisiella Song, 1996 and the family Pseudoamphisiellidae Song et al., 1997 has never been determined unequivocally. In their recent revisions, Berger [12] and Shao et al. [32] regarded this family as a peripheral group within the urostylids. Very recently, in their phylogenetic investigation, Yi et al. [7] suggested that the family Pseudoamphisiellidae should be transferred into the Discocephalida, which has yet to be defined but includes both the Pseudoamphisiellidae and the Discocephalidae. Morphologically, Pseudoamphisiella is considerably divergent from typical urostylid hypotrichs (e.g., Holosticha, pseudokeronopsids, and Urostyla) be- 
cause the cirri of its midventral rows are arranged in a separate, non-zig-zag pattern, and especially as there are/is no migrating cirri/row (frontoterminal cirri/row) during morphogenesis, which are formed characteristically from the posterior-most (right-most) FVT-cirral anlage [40]. In addition, the caudal cirri, which are lacking in all typical urostylids, are formed uniquely from the posterior end of each dorsal kinety anlage and the right marginal row has a unique de novo origin (i.e., appears as an independent anlage neighboring other FTV-primordia vs. being developed always intrakinetally within the parental structure in all other known hypotrichs) [12,32,38,41-45]. All these features cast strong doubt on the classification of Pseudoamphisiella, and therefore the family Pseudoamphisiellidae, among the urostylid hypotrichs.

Based on SSU rRNA sequences, pseudoamphisiellids are revealed as the sister group to the well-known discocephalines in all phylogenetic trees, although not with strong support. Nevertheless, this topology is consistent with both morphological (e.g., cephalized body shape, having a highly developed fiber system that connect cirri, generally two clearly separated ventral rows, and highly developed transverse cirri; for details see Table 2 and Figure 3) and general morphogenetic characters (e.g., the unique formation of the ventral rows during morphogenesis, which is clearly different from that of other typical hypotrichs) (Table 1) [5,9,32]. All such similarities suggest that the families Pseudoamphisiellidae and Discocephalidae should be assigned to the same assemblage, the order Discocephalida. However, these families are distinctive based on morphological, morphogenetic patterns, and SSU rRNA gene sequences (Table 2, Figure 3).

\subsection{Establishment of a new suborder: Pseudoam- phisiellina subord. $n$.}

According to the morphological, morphogenetic and molecular data, the family Pseudoamphisiellidae invariably represents a distinct evolutionary assemblage sufficiently divergent to warrant separation as a suborder within the order Discocephalida [5,6,9,32,38,44-46], thus a new suborder, Pseudoamphisiellina, is proposed.

\subsubsection{Diagnosis of suborder Pseudoamphisiellina subord. $n$.}

Slightly or non-cephalized Discocephalida with untypical midventral rows, that is, two distantly separated rows that morphogenetically derive with an urostylid pattern; the right-most midventral row formed from the anterior-most cirri by each FVT-anlage, positioned on the right side; no frontoterminal row present that is formed from the posterior-most FVT-cirral anlage during morphogenesis; marine habitat, psammophilic.

\subsubsection{Type family Pseudoamphisiellidae Song et al., 1997}

This new suborder is currently a monotypic taxon containing only the type family Pseudoamphisiellidae, in which two genera can be clearly assigned: Leptoamphisiella $\mathrm{Li}$ et al., 2007 and Pseudoamphisiella Song, 1996. It differs from the sister suborder Discocephalina in the body shape (only slightly or non-cephalized vs. typically cephalized), conspicuously different ciliature pattern (presence of non-migrating ventral row vs. absence; marginal rows uniform, nondifferentiated vs. conspicuously bipartite or reduced) and many morphogenetic features $[5,9,32,44,45]$. In addition, molecular data consistently indicate that both groups are distinct and form a clearly defined assemblage [46].

Table 2 Morphogenetic and morphological characteristics used for assessment of phylogenetic relationships among representatives of discocephalids and other spirotrichous genera ${ }^{\text {a) }}$

\begin{tabular}{lc}
\multicolumn{1}{c}{ Apomorph } & Plesiomorph \\
\hline 1. Stomatogenesis in hypo-apokinetal mode & in epi-apokinetal mode \\
2. New OP will be formed in the proter & now OP formed in the proter \\
3. UM in proter coming from de novo formed isolated UM-anlage & in non-5-cirral-anlagen mode \\
4. Cirral formation in 5-anlagen-mode, having 5-TC & in normal stichtrichous mode \\
5. Formation of caudal cirri in euplotid mode & present \\
6. Right marginal row absent & formed intrakinetally in each old row \\
7. DK anlagen not formed in each old row, often grouped & more than one on each side \\
8. One marginal row on each side & in primary mode \\
9. Dorsal kineties formed in secondary mode & in primary mode \\
10.FVT-cirral anlagen formed in secondary mode & only one undulating membrane \\
11.Having two undulating membranelles & non-cephalized \\
12. Cell with a 'head' or cephalized & fusion into a single mass \\
13.Ma nodules not fusing into a single mass during cell division & present \\
14. No mid-ventral rows & variable in number \\
15.Number of ventral cirral streaks very stable &
\end{tabular}

a) See Figure 3. Data sources: [5,6,9,11,12,32,33,37,38,40,43,47-51]. Abbreviations: DK, dorsal kineties; FVT, frontoventral-transverse; Ma, macronuclear; OP, oral primordium; TC, transverse cirri; UM, undulating membrane. *, This concerns the basic situation in which caudal cirri developed from the posterior end of right-most one or several dorsal kineties. 


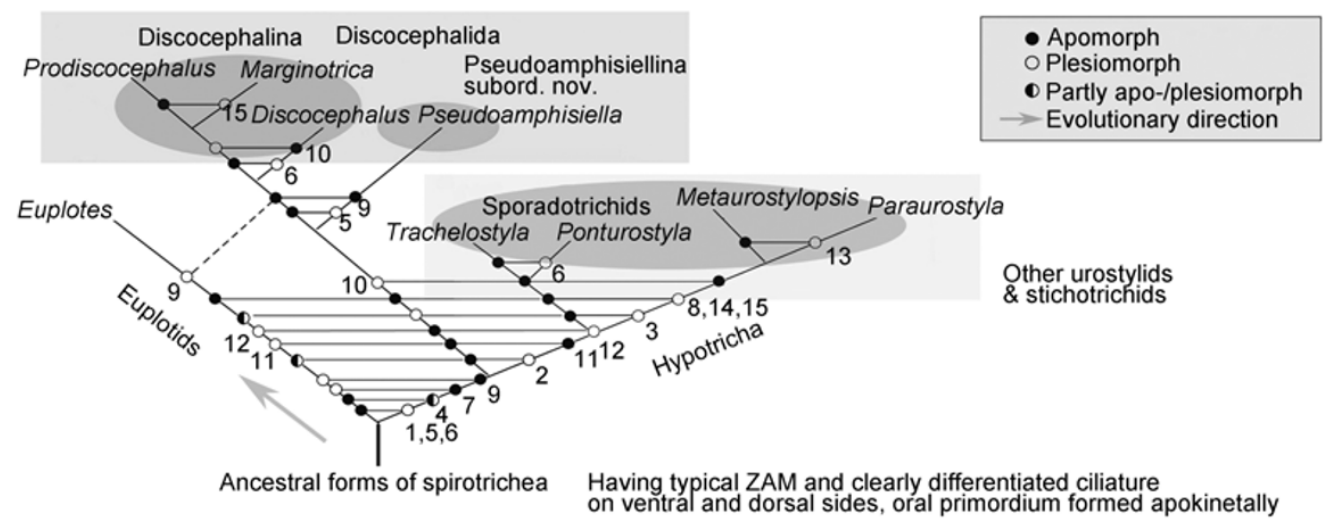

A

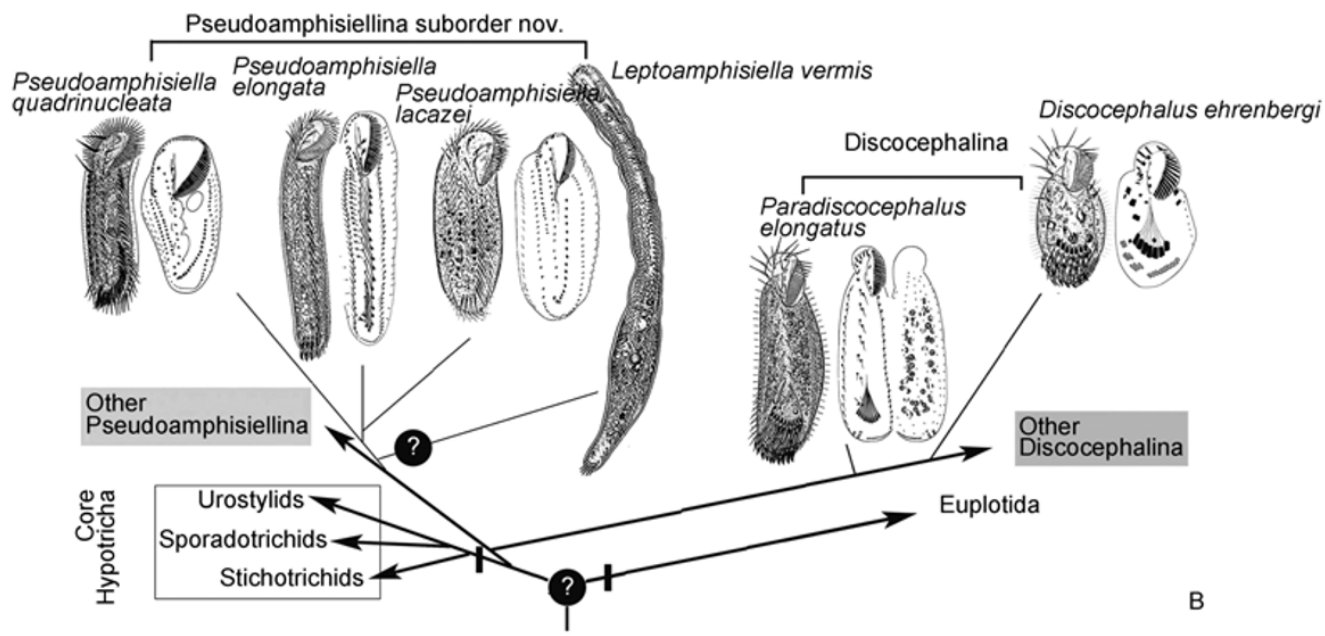

Figure 3 Assessment of the phylogenetic relationships among discocephalids and some other representative hypotrichs-euplotids based on morphological and morphogenetic information (A and B) (for explanation of numbered characters, see Table 2). Drawings of the representative forms that are analyzed in the present work are according to previous studies $[6,43,45,50]$ (with permission of the respective authors).

This work was supported by the National Natural Science Foundation of China (Grant Nos. 40906065 and 31030059). Our sincere thanks are given to Prof. Denis Lynn, University of British Columbia, Canada, for his critical suggestions during the preparation of the paper.

1 Corliss J O. The Ciliated Protozoa: Characterization, Classification and Guide to the Literature. 2nd ed. New York: Pergamon Press, 1979

2 Jankowski A W. Phylum Ciliophora Dofliein, 1901. In: Alimov A F, ed. Protista. Part 2, Handbook on Zoology (in Russian). St. Petersburg: Zoological Institute, Russian Academy of Sciences, 2007. 415--993

3 Lynn D H. The Ciliated Protozoa. New York: Pergamon Press, 2008

4 Small E B, Lynn D H. Phylum Ciliophora Doflein, 1901. In Lee J J, Hutner S H, Bovee E C, eds. An Illustrated Guide to the Protozoa. Kansas: Lawrence Press, 1985. 393-575

5 Wicklow B J. The Discocephalina (n. subord.): ultrastructure, morphogenesis and evolutionary implications of a group of endemic interstitial hypotrichs (Ciliophora, Protozoa). Protistologica, 1982, 18: 299-330

6 Li L, Song W, Al-Rasheid K A S, et al. Two discocephalid ciliates, Paradiscocephalus elongatus nov. gen., nov. spec. and Discocephalus ehrenbergi Dragesco, 1960, from the Yellow Sea, China (Ciliophora, Spirotrichea, Discocephalidae). Acta Protozool, 2008, 47: 353-362

7 Yi Z, Song W, Warren A, et al. A molecular phylogenetic investigation of Pseudoamphisiella and Parabirojimia (Protozoa, Ciliophora,
Spirotrichea), two genera with ambiguous systematic positions. Eur J Protistol, 2008, 44: 45-53

8 Yi Z, Lin X, Warren A, et al. Molecular phylogeny of Nothoholosticha (Protozoa, Ciliophora, Urostylida) and systematic relationships of the Holosticha-complex. Syst Biodivers, 2010, 81: 149-155

9 Shao C, Song W, Li L, et al. Systematic position of Discocephalus-like ciliates (Ciliophora: Spirotrichea) inferred from SS rRNA gene and ontogenetic information. Int J Syst Evol Microbiol, 2008, 58: 2962-2972

10 Song W, Shao C, Yi Z, et al. The morphology, morphogenesis and SS rRNA gene sequence of a new marine ciliate, Diophrys apoligothrix spec. nov. (Ciliophora; Euplotida). Eur J Protistol, 2009, 45: 38-50

11 Berger H. Monograph of the Oxytrichidae (Ciliophora, Hypotrichia). Monograph Biol, 1999, 78: 1-1080

12 Berger H. Monograph of the Urostyloidea (Ciliophora, Hypotricha). Monograph Biol, 2006, 85: 1-1304

13 Miao M, Shao C, Jiang J, et al. Caryotricha minuta (Xu et al., 2009) nov. comb., a unique marine ciliate (Protista, Ciliophora, Spirotrichea), with phylogenetics analysis of the ambiguous genus Caryotricha inferred from the small-subunit rRNA gene sequence. Int J Syst Evol Microbiol, 2009, 59: 430-438

14 Medlin L, Elwood H L, Stickel S, et al. The characterization of enzymatically amplified eukaryotic 16S-like rRNA-coding regions. Gene, 1988, 71: 491-499

15 Hall T A. BioEdit: a user-friendly biological sequence alignment editor and analysis program for Windows 95/98/NT. Nucleic Acids Symp Ser, 1999, 41: 95-98 
16 Nylander J A A. MrModeltest version 2. Distributed by the author. Department of Systematic Zoology, Evolutionary Biology Centre, Uppsala University, 2004

17 Yang Z. Maximum-likelihood estimation of phylogeny from DNA sequences when substitution rates differ over sites. Mol Biol Evol, 1993, 10: 1396-1401

$18 \mathrm{Gu}$ X, Fu X, Li H. Maximum likelihood estimation of the heterogeneity of substitution rate among nucleotide sites. Mol Biol Evol, 1995, 12: $546-557$

19 Guindon S, Gascuel O. A simple, fast and accurate method to estimate large phylogenies by maximum-likelihood. Syst Biol, 2003, 52: 696-704

20 Swofford D L. PAUP: Phylogenetic analysis using parsimony. Sunderland: Sinauer, 2002

21 Huelsenbeck J P, Ronquist F, Nielsen R, et al. Bayesian inference of phylogeny and its impact on evolutionary biology. Science, 2001, 294: 2310-2314

22 Saitou N, Nei M. The neighbor-joining method: a new method for reconstruction phylogenetic trees. Mol Biol Evol, 1997, 4: 406-425

23 Kimura M. A simple method for estimating evolutionary rates of base substitutions through comparative studies of nucleotide sequences. J Mol Evol, 1990, 16: 111-120

24 Felsenstein J. PHYLIP (Phylogeny Inference Package) Version 3.66. Distributed by the author. Seattle: Department of Genetics, University of Washington, 2006

25 Page R D M. TREEVIEW: An application to view phylogenetic trees on personal computers. CABIOS, 1996, 12: 357-358

26 Tamura K, Dudley J, Nei M, et al. MEGA4: Molecular evolutionary genetics analysis (MEGA) software version 4.0. Mol Biol Evol, 2007, 24: 1596-1599

27 Shimodaira H, Hasegawa M. CONSEL: for assessing the confidence of phylogenetic tree selection. Bioinformatics, 2001, 17: 1246-1247

28 Jankowski A W. Revision of the order Hypotrichida Stein, 1859. Generic catalogue, phylogeny, taxonomy (in Russian). Trudy Zool Inst Akad Nauk SSSR, 1979, 86: 46-85

29 Lynn D H, Small E. Phylum Ciliophora Doflein, 1901. In: Lee J J, Bradbury P C, Leedale G F, eds. An Illustrated Guide to the Protozoa. 2nd ed. Lawrence: Allen Press, 2002. 371-656

30 Tuffrau M. Proposition d'une classification nouvelle de l'ordre Hypotrichida (Protozoa, Ciliophora), fondée sur quelques données récentes. Anna Sci Nat Zool, 1987, 8: 111-117

31 Puytorac P de, Batisse A, Deroux G, et al. Proposition d'une nouvelle classification du phylum des protozoaires Ciliophora Doflein, 1901. C R Acad Sci II Sci Vie, 1993, 316: 716-720

32 Shao C, Song W, Warren A, et al. Morphogenesis of the marine ciliate, Pseudoamphisiella alveolata (Kahl, 1932) Song \& Warren, 2000 (Ciliophora, Stichotrichia, Urostylida) during binary fission. J Eukaryot Microbiol, 2006, 53: 388-396

33 Jiang J, Shao C, Xu H, et al. Morphogenetic observations on the marine ciliate Euplotes vannus during cell division (Protozoa: Ciliophora). J Mar Biol Assoc UK, 2010, 90: 683-689

34 Jiang J, Zhang Q, Warren A, et al. Morphology and SSU rRNA gene-based phylogeny of two marine Euplotes species, E. orientalis spec. nov. and E. raikovi Agamaliev, 1966 (Ciliophora, Euplotida). Eur J Protistol, 2010, 46: 121-132

35 Song W, Wilbert N, Chen Z, et al. Considerations on the systematic position of Uronychia and related euplotids based on the data of ontogeny and 18S rRNA gene sequence analyses, with morphogenetic redescription of Uronychia setigera Calkins, 1902 (Ciliophora, Euplotida). Acta Protozool, 2004, 43: 313-328

36 Jiang J, Song W. Two new Diophrys-like genera and their type species, Apodiophrys ovalis n. g., n. sp. and Heterodiophrys zhui n. g., n. sp. (Ciliophora: Euplotida), with notes on their molecular phylogeny.
J Eukaryot Microbiol, 2010, 57: 354-361

37 Song W, Wilbert N, Al-Rasheid K A S, et al. Redescriptions of two marine hypotrichous ciliates, Diophrys irmgard and D. hystrix (Ciliophora, Euplotida), with a brief revision of the genus Diophrys. J Eukaryot Microbiol, 2007, 54: 283-296

$38 \mathrm{Hu}$ X, Suzuki T. Observation on a Japanese population of Pseudoamphisiella alveolata (Kahl, 1932) Song et Warren, 2000 (Ciliophora: Hypotrichida): morphology and morphogenesis. Acta Protozool, 2006, 45: 41-52

39 Lin X, Song W, Warren A. Redescription of the rare marine ciliate, Protodiscocephalus borrori (Wicklow, 1982) from shrimp-culturing waters near Qingdao, China, with redefinitions of the genera Discocephalus, Prodiscocephalus and Marginotricha (Ciliophora, Hypotrichida, Discocephalidae). Eur J Protistol, 2004, 40: 137-146

40 Song W. Description of the marine ciliate Pseudoamphisiella lacazei (Maupas, 1883) nov. gen., nov. comb. (Protozoa, Ciliophora, Hypotrichida). Chin J Oceanol Limnol, 1996, 27: 18-22

41 Chen X, Gao S, Song W, et al. Parabirojimia multinucleata spec. nov. and Anteholosticha scutellum (Cohn, 1866) Berger, 2003, two marine ciliates (Ciliophora, Hypotrichida) from tropical waters in southern China, with note on their SSU rRNA gene sequences. Int J Syst Evol Microbiol, 2010, 60: 234-243

42 Chen X, Hu X, Kutsoka Y, et al. Morphology, morphogenesis and gene sequence of a freshwater ciliate, Pseudourostyla cristata (Ciliophora, Urostylida) from the ancient Lake Biwa, Japan. Eur J Protistol, 2010, 46: 43-60

43 Li L, Shao C, Song W, et al. Does Kiitricha (Protista, Ciliophora, Spirotrichea) belong to Euplotida or represent a primordial spirotrichous taxon? With suggestion to establish a new subclass Protohypotrichia. Int J Syst Evol Microbiol, 2009, 59: 439-446

44 Li L, Song W, Al-Rasheid K A S, et al. Morphology and morphogenesis of a new marine hypotrichous ciliate (Protozoa, Ciliophora, Pseudoamphisiellidae), including a report on the small subunit rRNA gene sequence. Zool J Linn Soc, 2010, 158: 231-243

45 Song W, Warren A, Hu X. Morphology and morphogenesis of Pseudoamphisiella lacazei (Maupas, 1883) Song, 1996 with suggestion of establishment of a new family Pseudoamphisiellidae nov. fam. (Ciliophora, Hypotrichida). Arch Protistenkd, 1997, 147: 265-276

46 Yi Z, Song W, Stoeck T, et al. Phylogenetic analyses suggest that Psammomitra (Ciliophora, Urostylida) should represent an urostylid family, based on small subunit rRNA and alpha-tubulin gene sequence information. Zool J Linn Soc, 2009, 157: 227-236

47 Eigner P, Foissner W. Divisional morphogenesis in Amphisiellides illuvialis n. sp., Paramphisiella caudata (Hemberger) and Hemiamphisiella terricola Foissner and redefinition of the Amphisiellidae (Ciliophora, Hypotrichida). J Eukaryot Microbiol, 1994, 41: 243261

48 Li L, Song W, Al-Rasheid K A S, et al. Redescription of a poorly known marine ciliate, Leptoamphisiella vermis Gruber 1888 n. g., n. comb. (Ciliophora, Stichotrichia, Pseudoamphisiellidae) from the Yellow Sea, China. J Eukaryot Microbiol, 2007, 54: 527-534

49 Shao C, Song W, Li L, et al. Morphological and morphogenetic redescriptions of the stichotrich ciliate Diaxonella trimarginata Jankowski, 1979 (Ciliophora, Stichotrichia, Urostylida). Acta Protozool, 2007, 46: 25-39

50 Shao C, Song W, Yi Z, et al. Morphogenesis of the marine spirotrichous ciliate, Trachelostyla pediculiformis (Cohn, 1866) Borror, 1972 (Ciliophora, Stichotrichia), with consideration of its phylogenetic position. Eur J Protistol, 2007, 43: 255-264

51 Shen Z, Lin X, Long H, et al. Morphology and SSU rDNA gene sequence of Pseudoamphisiella quadrinucleata $\mathrm{n}$. sp. (Ciliophora, Urostylida) from the south China sea. J Eukaryot Microbiol, 2008, 55: 510-514

Open Access This article is distributed under the terms of the Creative Commons Attribution License which permits any use, distribution, and reproduction in any medium, provided the original author(s) and source are credited. 